\title{
Ontogeny of long distance migration
}

\author{
Rebecca Scott,${ }^{1,2,5}$ Robert Marsh ${ }^{3}$ and Graeme C. Hays ${ }^{1,4}$ \\ ${ }^{1}$ Department of Biosciences, College of Science, Swansea University, Swansea SA2 8PP United Kingdom \\ ${ }^{2}$ Future Ocean, Department of Evolutionary Ecology of Marine Fishes, GEOMAR, Helmholtz Center for Ocean Research, \\ Dusternbrookerweg 20, Kiel 24105 Germany \\ ${ }^{3}$ Ocean and Earth Science, National Oceanography Centre, University of Southampton, Southampton SO14 3ZH United Kingdom \\ ${ }^{4}$ Centre for Integrative Ecology, School of Life and Environmental Sciences, Deakin University, Warrnambool, \\ Victoria 3280 Australia
}

\begin{abstract}
The movements of some long-distance migrants are driven by innate compass headings that they follow on their first migrations (e.g., some birds and insects), while the movements of other first-time migrants are learned by following more experienced conspecifics (e.g., baleen whales). However, the overall roles of innate, learned, and social behaviors in driving migration goals in many taxa are poorly understood. To look for evidence of whether migration routes are innate or learned for sea turtles, here for 42 sites around the world we compare the migration routes of $>400$ satellite-tracked adults of multiple species of sea turtle with $\sim 45000$ Lagrangian hatchling turtle drift scenarios. In so doing, we show that the migration routes of adult turtles are strongly related to hatchling drift patterns, implying that adult migration goals are learned through their past experiences dispersing with ocean currents. The diverse migration destinations of adults consistently reflected the diversity in sites they would have encountered as drifting hatchlings. Our findings reveal how a simple mechanism, juvenile passive drift, can explain the ontogeny of some of the longest migrations in the animal kingdom and ensure that adults find suitable foraging sites.
\end{abstract}

Key words: ARIANE particle tracking software; animal movement; biotelemetry; dispersal; habitat selection; NEMO ocean model; ocean currents; particle tracking; surface drifter buoys.

\section{INTRODUCTION}

In the animal kingdom, regular to-and-fro migrations between breeding and foraging habitats are widespread and may span many thousands of kilometers (e.g., Hein et al. 2012). Individuals often show high fidelity to their habitats (e.g., Bowen and Karl 2007, Broderick et al. 2007, Baracho-Neto et al. 2012), and consequently the drivers of these movements and the cues/behaviors used to optimize travel between distant sites have received a lot of attention in recent years (e.g., Alexander 1998, Alerstam et al. 2003, Chapman et al. 2010, Liedvogel et al. 2011, Mueller et al. 2013, Putman et al. 2013). For some species, migrations appear to evolve through social learning. For example, baleen whale calves (e.g., Megaptera novaeangliae) follow their mothers on their first migrations between tropical calving and highlatitude feeding areas and later return independently to these same sites (Weinrich 1998). Social learning is also commonly observed in many bird species (e.g., Columba livia and Grus americana), with individuals altering their routes when flying with more experienced conspecifics (Mueller et al. 2013, Pettit et al. 2013). For central place foragers, like some insect species, various cues (e.g.,

Manuscript received 25 November 2013; revised 19 March 2014; accepted 27 March 2014. Corresponding Editor: M. C. Wimberly.

${ }^{5}$ E-mail: beckyscott130@hotmail.com familiar landmarks) and path-integration techniques (in the absence of such cues) can drive the evolution of movement pathways to feeding areas (e.g., Schatz et al. 1999, Müller and Wehner 2010). For other species, key migratory decisions appear to evolve through innate processes; indeed, both the decision to migrate and migration directions have been shown to be genetically predetermined in some bird and insect species (e.g., Berthold and Helbig 1992, Mouritsen et al. 2013).

However, for many groups, the processes that shape both migration routes and foraging destinations remain enigmatic despite the wide availability of techniques for recording extended animal movements. For example, Lagrangian analyses of ocean currents and winds (e.g., from surface drifter buoys and ocean/atmospheric models) have gained great application for studying the movements of smaller organisms not amenable to large tracking devices, such as airborne insects, and drifting marine organisms such as early life-stage fish larvae and hatchling sea turtles (Chapman et al. 2012, Scott et al. 2012a, Baltazar-Soares et al. 2014). For larger mobile organisms such as sea turtles, large fish, marine mammals, and birds, satellite tracking has proved instrumental in detailing their migratory feats (e.g., Block et al. 2011).

Adult sea turtles (which are philopatric to their natal areas; Bowen and Karl 2007) have been particularly well studied through the use of satellite tracking technology (e.g., Godley et al. 2008). Synthesis of tracking data sets 
has highlighted a range of different post-breeding migratory strategies across populations of adult turtles: (1) oceanic and coastal movements to fixed neritic foraging grounds, (2) coastal shuttling between fixed or seasonal neritic sites, (3) local residence, and (4) pelagic foraging (Godley et al. 2008). Adult hard-shelled cheloniid turtles (e.g., Chelonia mydas, Caretta caretta, and Eretmochelys imbricata: family Cheloniidae) typically migrate across expanses of open ocean to discrete neritic foraging habitats. The tendency of cheloniid turtles to fast during oceanic crossings appears to place an upper migration limit of $\sim 3000 \mathrm{~km}$ on the distance an adult cheloniid turtle can travel from their breeding ground to their foraging ground (Hays and Scott 2013). However, migration strategies can vary both between and within different cheloniid turtle populations (e.g., Godley et al. 2008, Hays et al. 2010). Leatherback turtles (Dermochelys coriacea), the only species of soft-shelled turtle (Dermochelyiidae family), do not migrate to discrete habitats and instead forage pelagically. This foraging strategy frees this species from an upper migration limit, enabling the exploitation of very distant $(>11000 \mathrm{~km})$ foraging habitats (e.g., Benson et al. 2011). Thus, while satellite tracking studies have revealed that a range of post-breeding migration strategies is evident within the sea turtles, understanding the drivers that underpin the movement patterns and foraging habitat selections of adult turtles has remained enigmatic and highlighted the need for more quantitative and novel interdisciplinary approaches (e.g., Hays et al. 2010).

As hatchling turtles have relatively weak swimming abilities, ocean currents are thought to drive their broadscale dispersion into oceanic areas where the juveniles then grow for several years before recruiting to coastal subadult foraging sites closer to their natal area (e.g., Scott et al. 2012a). Upon reaching maturity, postbreeding sea turtles can perform open ocean crossings to the same fixed neritic foraging grounds year after year (e.g., Broderick et al. 2007). However, understanding how they select their particular foraging grounds has proved elusive. Recently a new paradigm was suggested, that this ontogenetic development of sea turtle migrations may be driven by ocean currents (Hays et al. 2010). In this study, the north/south dichotomy in the postbreeding migrations/foraging sites of adult turtles tracked from a breeding ground in the Mediterranean was hypothesized to reflect the north/south dichotomy in the local ocean circulation system (and hence hatchling dispersion patterns). Here, by combining global satellite tracking data sets to identify the movements of adult turtles, and using a global ocean model to identify the movements of hatchling sea turtles, we globally assessed the ontogeny of long-distance movements for sea turtles that may initially drift passively but then subsequently move more actively as they grow into large, powerful swimmers. In so doing, we provide compelling global support that ocean currents drive the ontogeny of cheloniid sea turtle migrations through two main mechanisms. Cheloniid turtles either migrated to neritic foraging sites they would have passively drifted to as hatchlings (albeit, typically on more direct active migration routes), or when hatchlings drifted to unsuitable adult neritic foraging sites, turtles performed less typical migration strategies: either coastal shuttling to fixed/seasonal habitats, local residence, or oceanic foraging. The movements of leatherback turtles (the only non-cheloniid species) are more directly shaped by ocean currents that drive the distribution of their drifting pelagic food sources. Hence, while many small organisms and juvenile life stages of larger organisms are reliant on current flows for long-distance dispersal (Chapman et al. 2011), here we provide the first compelling evidence that ocean current flows also drive (both directly and indirectly) the evolution of active migrations for large mobile adult sea turtles.

\section{Materials and Methods}

We combined published satellite tracking data of $>400$ adult sea turtles (families Cheloniidae and Dermochelyidae) from 42 nesting sites with $>40000$ Lagrangian-derived drift trajectories generated from (1) a 30-year database of surface drifter buoy tracks and (2) seven years of ocean model particle tracking simulations. Details on the post-breeding migrations of satellite-tracked adult turtles were obtained from published maps following the methodology of Hays and Scott (2013). Due to the wealth of satellite tracking data, details of the individual satellite tracking studies are included in the supplemental material (Appendix A: Figs. A1-A4). Hatchling drift scenarios were assessed using Lagrangian surface drifter buoys from the Global Drifter Program (Global Drifter Program data available online $^{6}$ that passed within $150 \mathrm{~km}$ of nesting sites. Simulated particle tracks were generated using ARIANE particle tracking software (program available online). ${ }^{7}$ Also used was the global eddy-permitting ( $1 / 4^{\circ}$ resolution) NEMO ocean model (Madec 2008, Scott et al. 2012b) that has been run in hindcast mode from 1958 to 2007. From each nesting location, 1000 ARIANE particles were released 10-60 km offshore and assigned a start date by randomly selecting a year between 2000 and 2006 and a day of the year during the population's peak hatchling season (typically a 2-3 month window). Fixing the number of released particles at 1000 per nesting location was a pragmatic decision to help ensure data sets were sufficiently large for our subsequent statistical analysis but at the same time not too computationally demanding for model simulations over multiple sites. By sampling a wide range of possible trajectories per nesting location, we account for both seasonal and interannual variability, and

\footnotetext{
${ }^{6} \mathrm{http}: / /$ www.aoml.noaa.gov/envids/gld/

7 http://stockage.univ-brest.fr/ grima/Ariane/
} 
chaotic mesoscale (eddy) variability of ocean currents in the NEMO hindcast.

Most cheloniid turtle populations migrate through coastal and oceanic waters to reach discrete neritic foraging sites. For these populations, travel bearings were taken when adult migration and hatchling dispersal paths reached distances of $500 \mathrm{~km}$ from nesting beaches. This distance was selected as it best captured the general travel directions of both drifters and adult turtles as: (1) coastal processes often made it difficult to identify the initial (or general) travel direction of buoy/particle trajectories until they had established their course beyond the coastal realm, and (2) $500 \mathrm{~km}$ captured the general travel directions of turtles that performed migrations of this magnitude, while ensuring a maximum number of buoys/particles were still drifting at this distance. Turtles traveling within $15^{\circ}$ of drifters were considered to be traveling in agreement with ocean current flows. A window of $15^{\circ}$ was a pragmatic choice, due to the chaotic influence of mesoscale variability on drift. For each breeding area, we generated 1000 sets of turtle bearings, assuming a random departure direction from the nesting beach. For example, if 12 adults had been satellite tracked $>500 \mathrm{~km}$ from a beach, we generated 1000 sets of 12 random departure directions $500 \mathrm{~km}$ from the nesting beach. This provided a null model against which to compare the adult tracking and particle tracking results. We then assessed the proportion of the randomly generated sets of adult travel bearings that were within $15^{\circ}$ of one of the 1000 particle tracking or buoy bearings. For example, in the case just mentioned, for each of the 1000 simulations of 12 randomly selected departure directions, we assessed the proportion of those 12 random bearings that were within $15^{\circ}$ of one of the 1000 particle tracking or buoy bearings. Likewise, we compared the actual proportion of tracked turtles that were within $15^{\circ}$ of one of the 1000 particle tracking or buoy bearings. This analysis was conducted to assess if significantly more turtles were observed to travel in the same direction (within $15^{\circ}$ of drift bearings) as ocean current flows than expected by chance, based on the randomly generated simulated travel bearings. For cheloniid turtle populations where all turtles were nonmigratory or all turtles performed entirely coastal shuttling migrations, these simulations were not carried out, as migration directions were not relevant or constrained to two directions along the coast. For populations where all turtles foraged oceanically (e.g., all leatherback turtle populations), the relationships between broad-scale population movement patterns and ocean circulation patterns were examined.

\section{RESUlts}

Published satellite tracking data were obtained from 42 nesting sites where 3 to $>100$ turtles had been tracked on their post nesting migrations (see Appendix A for Figs. A1-4 and satellite tracking references). Data were available for 243 cheloniid turtles; 78 loggerhead turtles
(Caretta caretta), 26 green turtles (Chelonia mydas), 17 hawksbill turtles (Eretmochelys imbricata), and 21 olive ridley turtles (Lepidochelys olivacea). No data were available for two cheloniid species; the flatback turtle (Natator depressus) and Kemp's ridley turtle (Lepidochelys kempii). Data on the general movements of leatherback turtles were based on satellite tracking deployments on $>200$ leatherback turtles (Dermochelys coriacea).

A total of 1398 Lagrangian drifter buoys passed within $150 \mathrm{~km}$ of nesting sites, enabling 1794 1-yr-long Lagrangian hatchling drift trajectories to be derived (as some buoys passed the vicinity of $>1$ nesting sites; Fig. 1). Using ARIANE with the NEMO hindcast data, a total of 42000 1-yr-long Lagrangian trajectories were computed, which produced $>3$ million modeled particle locations (see Appendix A: Fig. A1). While drifter buoys provided empirical observations of ocean currents to verify model simulations, analysis of the NEMO hindcast enabled more detailed investigation into ocean currents experienced by hatchlings, with 1000 Lagrangian trajectories computed during the peak hatchling season at each of the 42 nesting sites. Model (in silico) Lagrangian trajectories and in situ Lagrangian buoy trajectories revealed the same large-scale ocean circulation patterns (see Appendix B: supplementary video).

\section{Hard shelled sea turtles (Cheloniidae family)}

While adult cheloniid turtles do not generally drift with ocean currents, our evidence suggests that for all cheloniid turtle species and populations, ocean currents drive the development of an individual's post-breeding migration through two main mechanisms.

Mechanism one.-Adult cheloniid turtle populations typically perform directed migrations, which include open ocean crossings to coastal foraging habitats several hundreds to $\sim 3000 \mathrm{~km}$ from their breeding beaches (Hays and Scott 2013). For these populations, individual turtles from all cheloniid species consistently migrated to foraging habitats that they would have encountered as hatchlings. At breeding grounds where ocean currents showed strong directionality (low circular SD of drift direction bearings; Fig. 2; black symbols), turtle migration routes were also observed to follow strong and overlapping directionality (Fig. 3 and Appendix A: Fig. A2a, b). At breeding beaches where ocean currents were more dispersed and variable (higher circular SD of drift direction bearings; Fig. 2; white symbols), the migration routes of cheloniid turtles were also observed to either be more dispersed, or turtles migrated directly to a subset of potential sites they would have encountered (albeit, often along more convoluted indirect drift routes; Fig. 4a, b, Appendix A: Fig. A2c-o).

Mechanism two.-At breeding sites where the potential "downstream" coastal foraging sites that cheloniid hatchlings would drift to exceeded $3000 \mathrm{~km}$ (Fig. 2; gray symbols), cheloniid adult turtles performed less typical migration patterns. Instead of embarking on directed 


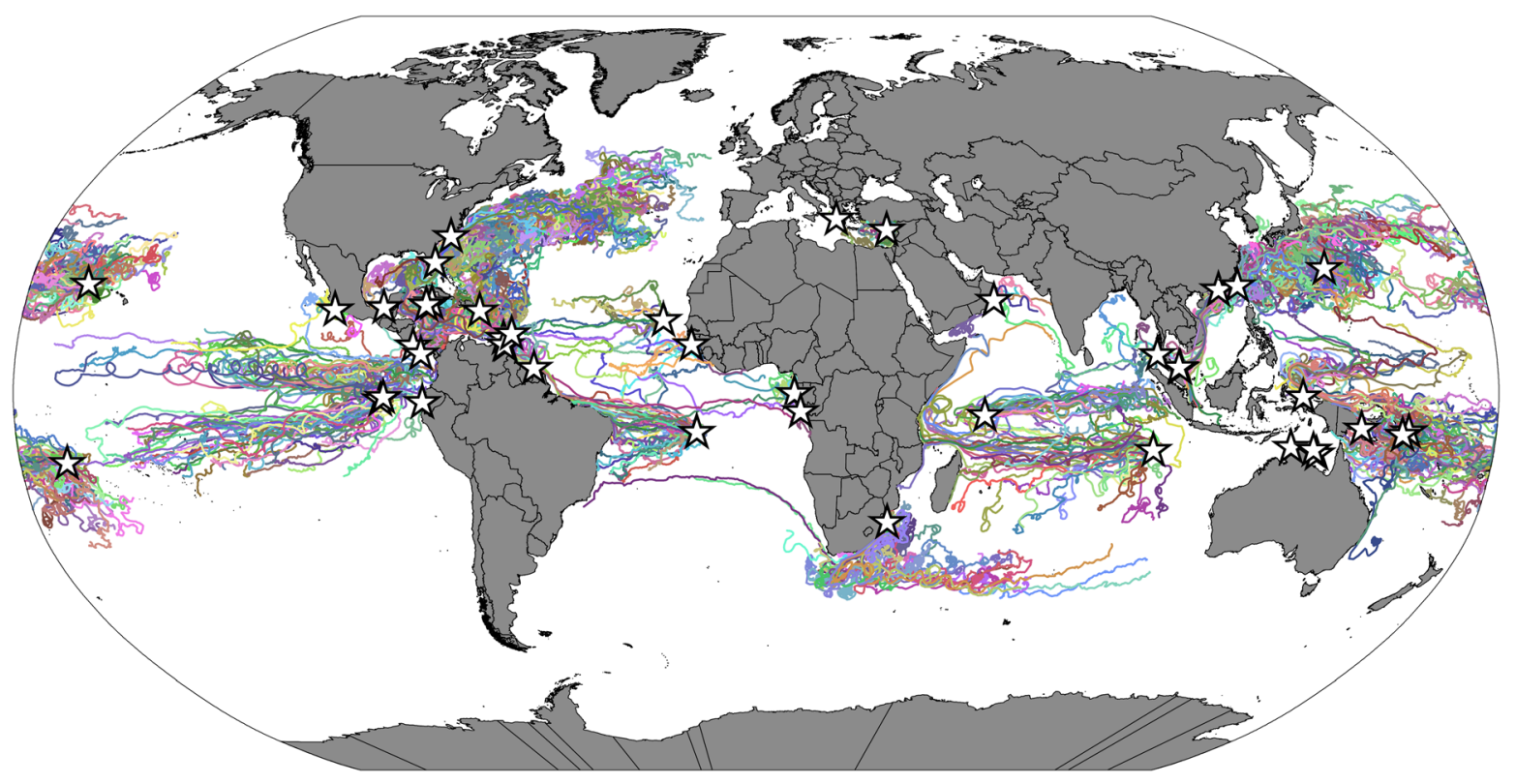

FIG. 1. Examples of hatchling drift scenarios from 42 nesting sites (white stars). Colored lines show 1794 1-yr-long trajectories derived from surface drifter buoys (spanning 1981-2011). Colors differentiate the trajectories. The large-scale circulation depicted from these buoys is broadly similar to that observed in particle tracking model outputs (see Appendix A: Fig. A1 and Appendix B): within $\pm 15^{\circ}$ of the equator, flows are predominantly westward, incorporating some Ekman divergence about the equator itself; in the subtropics, drifts follow the major western boundary currents, most conspicuously the Gulf Stream, the Kuroshio, the Agulhas, and the East Australian Currents; elsewhere in the subtropics, flows are sluggish and less organized.

migrations to discrete neritic habitats, turtles were observed to adopt one of three alternative strategies; coastal shuttling, local residence near their breeding areas, or oceanic foraging (Fig. $4 \mathrm{c}-\mathrm{e}$ and Appendix A: Fig. A3a-c).

The two mechanisms through which local ocean circulation patterns were shown to drive the ontogeny of migration for adult cheloniid turtles were population and not species specific. The migrations of all cheloniid turtle species could be explained by these two mechanisms, with the same species (and indeed individuals from the same nesting populations) adopting different strategies based on the local conditions they are predicted to have encountered while dispersing as hatchlings from their breeding grounds.

Support for the first mechanism was strongest from breeding sites with strong directionality in ocean currents. At these sites, adult turtles showed strong directionality in their post-breeding movements, which were significantly oriented with the direction of ocean current flows. For example, at Ascension Island (equatorial Atlantic), all of the 20 tracked green turtles and Lagrangian drifters traveled broadly west toward the coast of Brazil (Fig. 3a). From another four sites; Zakynthos (Mediterranean; Fig. 3b), China (Guangdong province; Fig. 3c), Taiwan (South China Sea; Fig. $3 \mathrm{~d}$ and Appendix A: Fig. A2a), and Puerto Rico (Caribbean; Fig. 3e and Appendix A: Fig. A2b) all turtles and drifters traveled broadly either (1) north and south or (2) east and west in line with strong bifurcation in current flows at the respective breeding beaches. At all these sites, significantly more turtles than expected by chance migrated in the same direction as ocean current flows $(P<0.002$ in all cases; Fig. 3).

Further support for the first mechanism came from breeding sites where ocean currents were more variable and dispersed. Here, turtle migrations were also widely dispersed or directed toward a subset of a range of habitats encountered along passive dispersal routes. For example, $>30$ green and olive ridley turtles tracked from three different nesting sites in northern Australia migrated to a range of different foraging habitats along a subset of a broad range of drift trajectories (Fig. 4a, Appendix A: Fig. A2c, d). All drifters from Tortuguero National Park (on the Caribbean coast of Costa Rica) initially drifted east along the coast of Panama toward Columbia in a large standing eddy before looping back broadly northwest toward Nicaragua, Honduras, Belize, and Mexico. All 12 green and hawksbill turtles tracked from this site migrated broadly northwest along more direct routes, and opposing the initial eastward flowing currents, to foraging grounds in Nicaragua, Honduras, and Belize that they would have encountered while drifting (Fig. 4b). Hence at these sites, while turtles do not necessarily migrate in the same direction as ocean currents, turtles still all migrated to sites that they are expected to have encountered while drifting (see also Appendix A: Fig. A2e-o).

All sites where the nearest potential adult coastal foraging areas downstream (as determined by ocean 

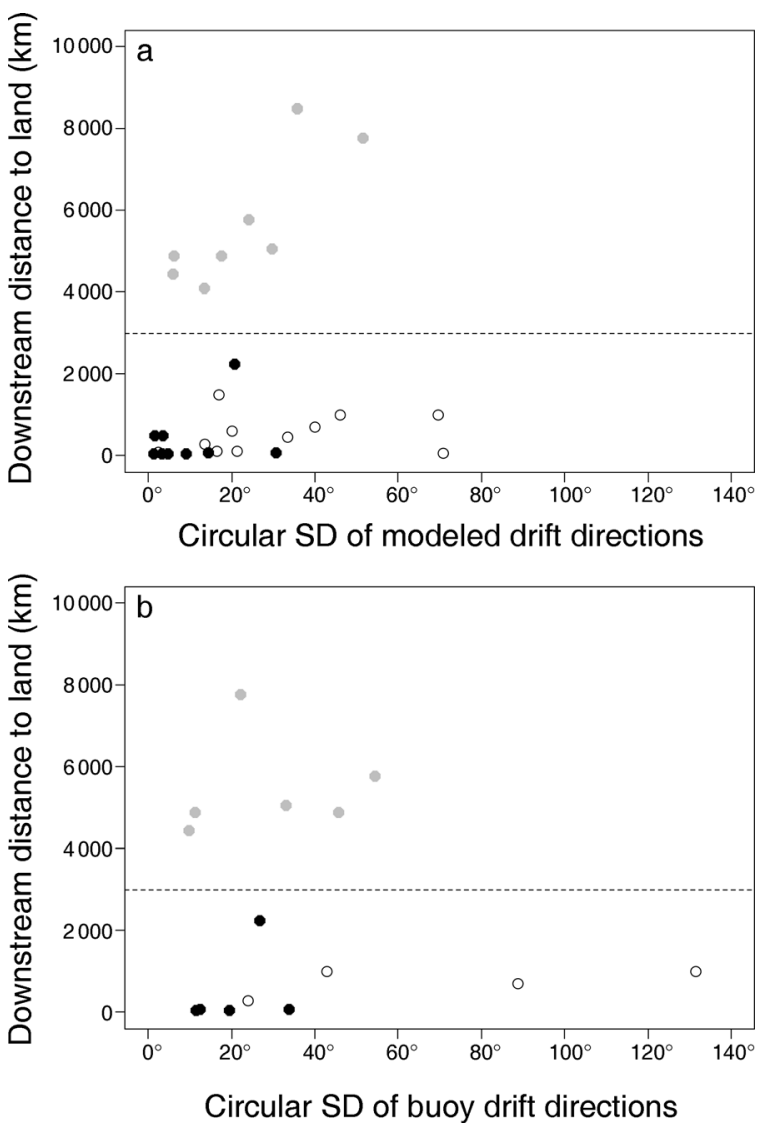

FIG. 2. Dispersion of (a) simulated model and (b) empirical surface buoy drift trajectories (based on the spread-circular SD of drift trajectories, and downstream distance to nearest land mass) vs. the corresponding migration strategy designated for that cheloniid turtle breeding population. Black circles correspond to turtle populations (e.g., Ascension Island and Zakynthos) where adult migrations and hatchling drift trajectories were designated as showing strong and overlapping directionality. Open circles correspond to populations (e.g., in northern Australia) where adult migrations and hatchling drift trajectories were designated as more dispersed and variable. Gray circles correspond to populations (e.g., in North Carolina, USA and the Cocos [Keeling] Islands) where ocean circulation patterns transported hatchlings to sites too far away $(>3000$ $\mathrm{km}$; dashed line) to return from as adults.

current flows) were $\sim 4000-8000 \mathrm{~km}$ from the natal area (and thus exceeding the upper observed/predicted limit on adult migration distances; Hays and Scott 2013) provided support for the second mechanism. At these sites, turtles adopted one of the less typical postbreeding migration strategies (Fig. 4c-e, Appendix A: Fig. A3a-c). At island archipelago nesting rookeries, turtles either remained locally resident, as was the case for the nonmigratory green turtles breeding in the Indian Ocean's Cocos (Keeling) Islands (Fig. 4d), or foraged relatively nearby in oceanic waters, as was the case for some loggerhead turtles tracked from the eastern Atlantic Cape Verde Islands (Fig. 4c). At mainland nesting rookeries, turtles tended to perform entirely coastal shuttling migrations (avoiding any open sea crossings). For example, loggerhead turtles from North Carolina shuttled north and south along the coast to seasonal neritic habitats along the eastern U.S. coast (Fig. 4e). Furthermore, distances of the nearest potential adult cheloniid neritic foraging grounds downstream of prevailing ocean current flows were significantly further at those sites supporting mechanism two vs. mechanism one (Mann-Whitney Wilcoxon test, $W=351 ; P<0.001$, mean $5781 \mathrm{~km} ; \mathrm{SD}=1525 \mathrm{~km}$ and mean $600 \mathrm{~km} ; \mathrm{SD}=$ $555 \mathrm{~km}$ respectively).

\section{Leatherback turtles (Dermochelyidae family)}

Leatherback turtle movements seem to be shaped by ocean currents through more direct processes, whereby ocean currents directly influence their prey distributions and thus their broad-scale movement patterns are in accordance with the broad-scale patterns in ocean circulation. For example, the foraging movements of leatherback turtles tracked from South Africa were in close association with the southward-flowing Agulhas current and areas of high eddy activity, which would shape the dispersal of hatchling leatherback turtles and the distribution of the pelagic prey items consumed by this species (Fig. 4f). In the North Atlantic, migrating adult leatherback turtles and drifting hatchling turtles from four nesting regions all dispersed widely throughout this ocean basin in agreement with the patterns of the surface ocean current systems (Appendix A: Fig. A4a). This was also apparent in other ocean basins, e.g., from nesting rookeries in the Indo-Pacific region, adult turtles migrations were again consistent with the general patterns in the surface ocean circulation and hatchling drift (Appendix A: Fig. A4b-d).

\section{Discussion}

Our study provides an advance in the study of animal migration, by providing strong evidence for the hypothesis that the passive drift experiences of early life stages may shape adult migration routes for a well known group of migrators, the sea turtles. This pattern contrasts with the processes that shape migration and movement routes to foraging sites in other taxa, where social learning or innate behaviors (e.g., compass bearings) are often important. While the hatchling dispersal phase is the least understood sea turtle lifehistory stage, we highlight that the importance of studying hatchling dispersal extends beyond the direct implications for the early life-history stages, to implications for turtles throughout adulthood.

The foraging location of adult turtles can be defined in terms of (1) the direction from the nesting area and (2) the distance. Our evidence highlights the interplay between distance and direction and the fact that ocean currents drive the ontogenetic development of both these components of migration, developing arguments made in a previous study focusing on an individual breeding site (Hays et al. 2010). For adult cheloniid sea turtles, 

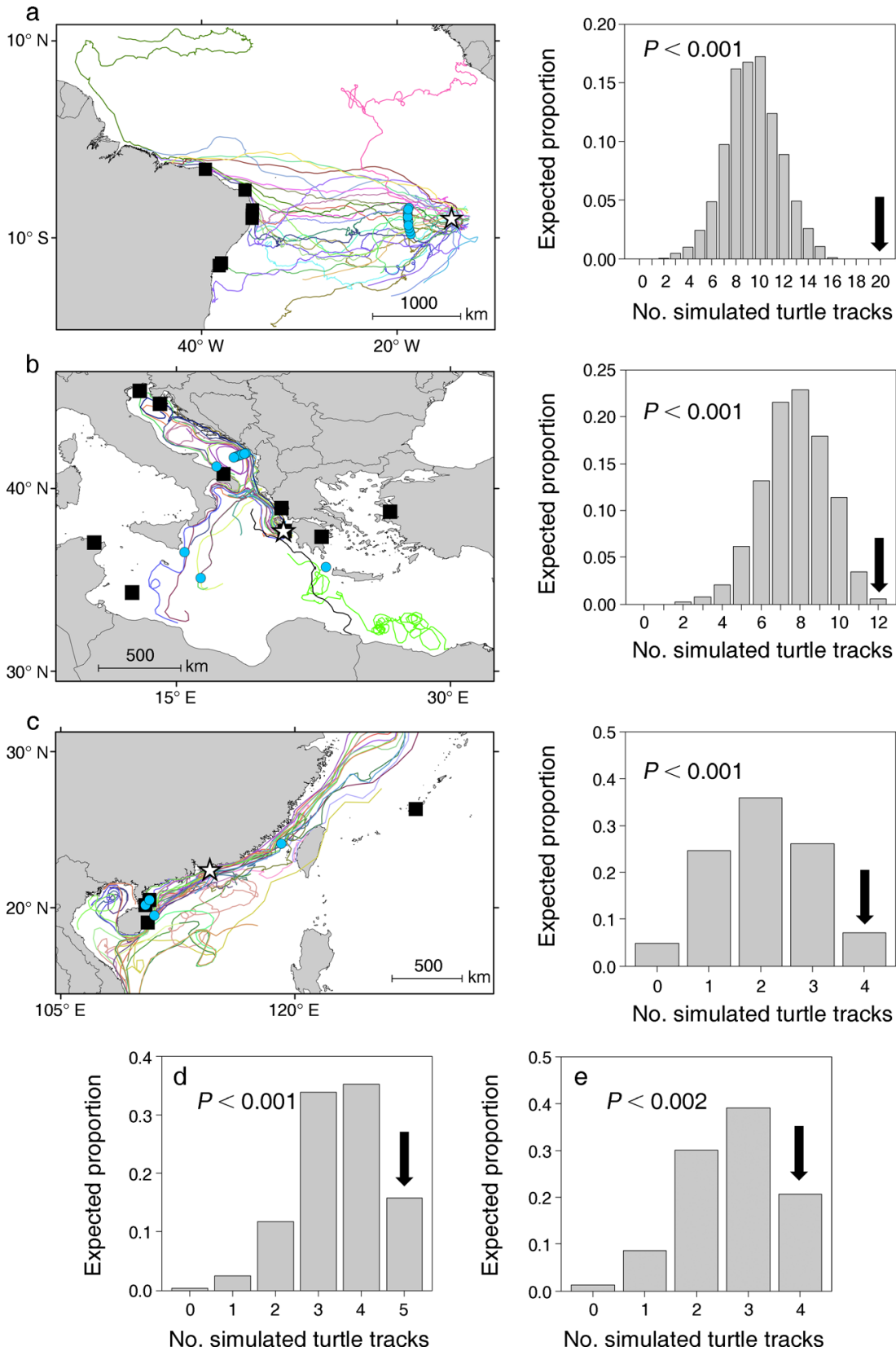

FIG. 3. Sites where adult turtle tracks and drifter routes showed strong and significantly overlapping directionality (mechanism one populations). Maps depict adult turtle foraging locations (black squares) and adult turtle locations at $500 \mathrm{~km}$ (blue circles; used to derive travel bearings) from their nesting sites (white stars). Colored lines depict the range of drift trajectories at each site. Histograms depict the number of tracked turtles that traveled $>500 \mathrm{~km}$ that were observed to travel in the same direction (within $15^{\circ}$ ) as drift trajectories and the expected proportion traveling in the same direction as drift trajectories based on 1000 sets of randomly generated turtle travel bearings (see Methods). Significantly more turtles were observed (indicated by solid arrows in each histogram) to travel in the same direction as drift trajectories than could be expected by chance alone ( $P<0.002$ in all cases). (a) Green turtles $(n=20)$ tracked from Ascension Island (Papi et al. 2000, Hays et al. 2002). All turtles and drifters traveled west toward the coast of Brazil. (b) Loggerhead turtles $(n=17)$ tracked from Zakynthos (see Hays et al. 2010). Twelve turtles migrated $>500 \mathrm{~km}$, the majority of turtles and drifters $(>90 \%)$ traveled north to the Adriatic, and the remaining three turtles that migrated $>500 \mathrm{~km}$ and drifters traveled broadly southeast or southwest. (c) Green turtles $(n=4)$ tracked from China (Song et al. 2002, Chan et al. 2003). Three turtles (and 76\% of drifters) migrated west-southwest to south China, while one turtle (and $14 \%$ of drifters) traveled northeast toward Okinawa Island, Japan. (d) Green turtles $(n=8)$ tracked from Taiwan (Cheng 2000; see also Appendix A: Fig. A2a). Five turtles migrated $>500 \mathrm{~km}$, all turtles migrated broadly northeast or southwest toward Japan and China in accordance with the bifurcation of drifters. (e) Hawksbill turtles $(n=15)$ tracked from Mona Island, Puerto Rico (Van Dam et al. 2008; see also Fig. A2b). Eight turtles foraged around Puerto Rico, four migrated $>500 \mathrm{~km}$ broadly east or northwest toward other Caribbean islands, and three traveled broadly west to the Dominican Republic, Nicaragua, and Honduras. Lagrangian drifters traveled broadly east, north, and northwest $(\sim 60 \%)$, the rest traveled broadly west along the southern coast of the Dominican Republic, and toward Nicaragua, Honduras, Belize, and Mexico. 
the upper ceiling on migration distance between breeding and foraging areas seems to be around 3000 $\mathrm{km}$, with this ceiling set by the maximum fat store available to sustain fasting during oceanic crossings (Hays and Scott 2013). Our evidence suggests that this ceiling seems to drive the migration behavior of adult turtles. For example, for some breeding sites, hatchlings would drift to mainland sites $>3000 \mathrm{~km}$ away, such as the Cocos (Keeling) Islands (Indian Ocean) where green turtles nest (Whiting et al. 2008). These very distant foraging sites (e.g., the coast of Africa and Madagascar for hatchlings drifting from the Cocos Islands) may contain good adult foraging areas (e.g., see Hughes 1974), but exceed the ceiling for their regular breeding migrations. Hence in these cases, instead of the more typical adult cheloniid post-breeding migrations through oceanic waters to discrete neritic foraging grounds (shaped by mechanism one of the hypotheses), we found that adult turtles tended to adopt one of the less typical migration strategies such as pelagic foraging (e.g., Hawkes et al. 2006) or residence at the breeding grounds from more isolated island rookeries (Whiting et al. 2008) or coastal shuttling to fixed/seasonal habitats from mainland nesting rookeries (e.g., Hawkes et al. 2007). For turtles adopting these less typical strategies (consistent with mechanism two of our drift hypothesis), the movements and foraging areas of these turtles are likely to be driven by previous experiences after the juvenile oceanic development phase is over and turtles start recruiting back to subadult coastal development habitats close to their natal areas. Indeed, some juvenile turtles have been directly tracked recruiting back to foraging sites close to their breeding grounds (Nichols et al. 2000, Eckert et al. 2008, Peckham et al. 2011). This upper limit on migration distance in sea turtles contrasts with that of other taxa. For example, birds can migrate much further than swimming migrants (e.g., Hein et al. 2012, Hays and Scott 2013) due to the higher travel speeds they can attain (e.g., Alexander 1998). Indeed, this enables birds such as Sooty Shearwaters (Puffinus griseus) and Arctic Terns (Sterna paradisaea) to perform annual migrations that can span $>17000 \mathrm{~km}$ between the Arctic and Antarctic, to take advantage of an endless summer, and to exploit seasonally available resources (Shaffer et al. 2006, Egevang et al. 2010).

For cheloniid turtle populations, the two variants of the hatchling drift mechanism could be used to explain all the different adult post-nesting migration strategies. However, leatherback turtles have a fundamentally different pattern of movement and foraging ecology. In contrast to adult cheloniid turtles, leatherbacks do not maintain close fidelity to foraging grounds, but instead are great ocean wanderers/pelagic foragers. They consequently forage in transit and have a pattern of broad-scale pan-oceanic movements that can extend up to $11000 \mathrm{~km}$ from their breeding grounds (e.g., Benson et al. 2011). Nevertheless, even for these ocean wanderers, hatchling drift patterns can explain their broad patterns of movement, such as the tendency for leatherbacks nesting in the North Atlantic region to remain in that ocean basin rather than traveling to the South Atlantic and vice versa. Furthermore, ocean currents directly influence their drifting prey distributions, which are concentrated by oceanographic features such as mesoscale eddies, convergences, and upwellings (e.g., Lambardi et al. 2008). Indeed, a previous, more detailed analysis into the tracks of nine leatherback turtles tracked from South Africa revealed that the movements of these turtles were virtually indistinguishable from those of passive Lagrangian drifters, with the variability in ocean currents and eddy activity explaining their route variability and foraging hotspots (Lambardi et al. 2008). The movements of adult leatherback turtles are thus likely to be shaped by the interplay between local prey distributions and their past experiences as drifting hatchlings.

Given the high mortality rates of hatchling sea turtles, which have a protracted and highly dispersive juvenile life stage, one would expect a strong selective pressure for turtles that survive to maturity to imprint on (and return to) foraging sites that they had encountered along successful drift routes. Indeed, the ability to return to habitats is well documented in breeding sea turtles, which can be highly philopatric to their natal areas and also show high fidelity to their foraging habitats (Bowen and Karl 2007, Broderick et al. 2007). Other marine species with juvenile dispersal phases, such as salmon, also imprint on natal sites as juveniles and later return as adults (Putman et al. 2013), and there is increasing evidence that a range of species, including sea turtles and salmon, are able to use information from the Earth's magnetic field to return to target sites (Lohmann et al. 2008, Putman et al. 2013). Interestingly, our evidence for imprinting on sites encountered by passive drift provides an explanation for the conundrum that adult sea turtles often travel extended distances from their breeding sites to their foraging grounds, when suitable foraging grounds exist much closer.

The processes that drive differences in the ontogeny of migration across taxa are enigmatic, e.g., social learning vs. innate behaviors vs. passive drift. Social learning (e.g., in whales) can arise, for example, when there is extended parental care of the offspring, so by necessity the offspring travel with their parents for long periods and hence learn migration routes (Weinrich 2008). In contrast, in sea turtles there is no parental care: after egg laying, adult sea turtles have no further interactions with their developing eggs or hatchlings. In this situation, one possibility is that turtles might have an innate tendency to travel to certain sites, as has been shown in some bird and insect species (e.g., Berthold and Helbig 1992, Mouritsen et al. 2013). However, our evidence that locations encountered by passive drift provide a good explanation of subsequent adult foraging sites makes an argument against innate selection of foraging locations in sea turtles. In birds, the innate behavior seen in first- 

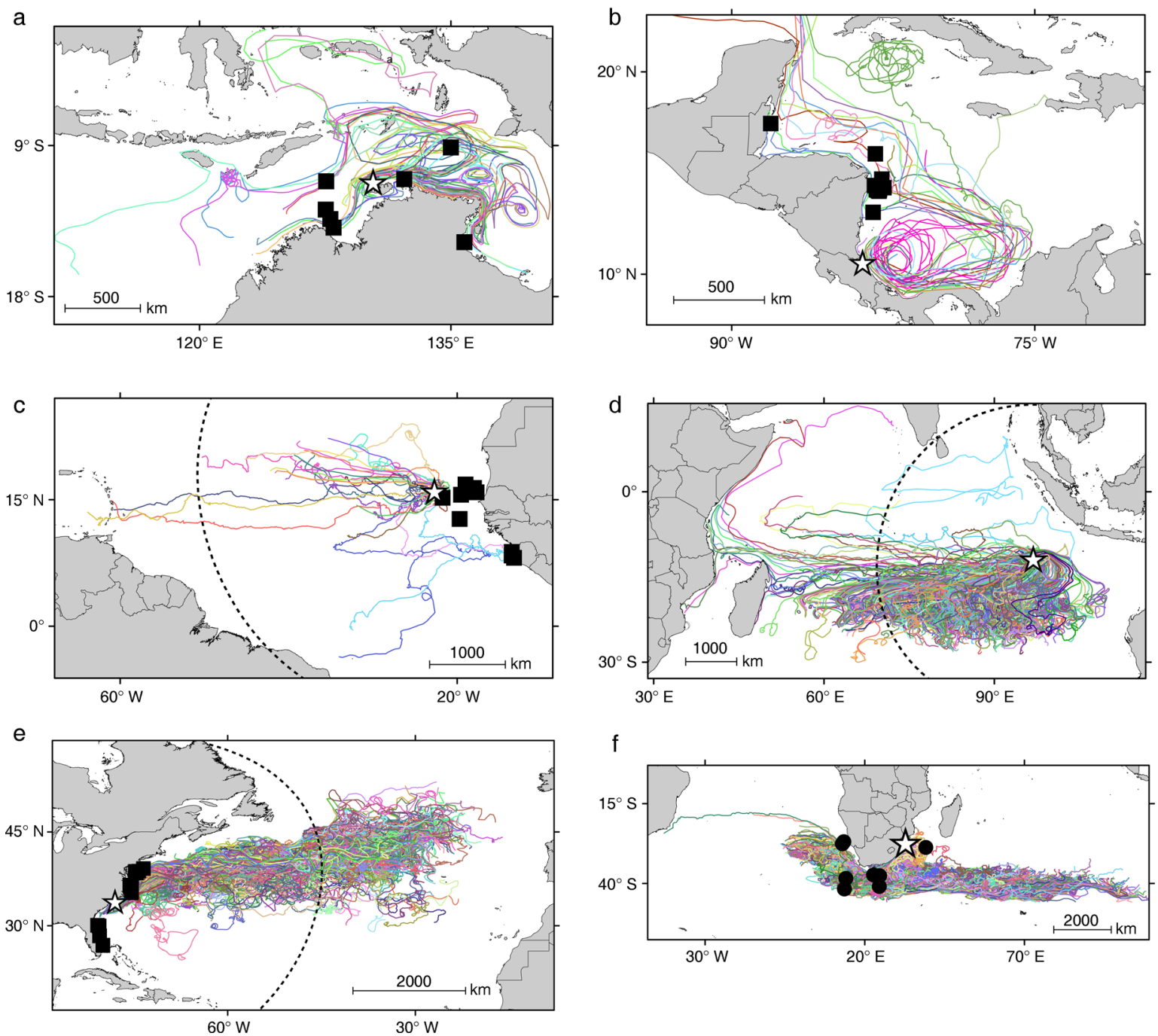

FIG. 4. Sites where (a-c) drift trajectories and adult cheloniid turtles migrations were more dispersed (mechanism one), or (c-e) where the nearest land mass downstream of currents was too far for adult cheloniid turtles to return to (mechanism two), or (f) where broad-scale patterns in ocean circulation reflect broad-scale movements of oceanic foraging leatherback turtles. (a) Olive ridley turtles $(n=8)$ tracked from the Tiwi Islands, North Australia (Whiting et al. 2007). Adult turtles migrated along a subset of a range of potential drift routes to their foraging habitats. (b) Green and hawksbill $(n=12)$ turtles tracked from Tortuguero, Costa Rica (Troëng et al. 2005a, $b$ ). All drift trajectories were initially entrained in an area of high eddy activity, drifting broadly toward Panama and Columbia before looping back and drifting northwest toward Nicaragua, Honduras, and Belize. All adult turtles migrated along more direct routes broadly northwest to Nicaragua, Honduras, and Belize. (c) Oceanic vs. neritic foraging loggerhead turtles $(n=10)$ from the Cape Verde Islands (Hawkes et al. 2006). Seven turtles foraged in oceanic waters, while three turtles migrated southeast to the coast of Sierra Leone; the only land mass encountered by drifters within $3000 \mathrm{~km}$ (dashed line) of the natal area. Prevailing drift routes transported hatchlings into the open ocean and to very distant $(>4000 \mathrm{~km})$ land masses. Thus, this site provides support for both mechanisms one and two. (d) Nonmigratory green turtles $(n=6)$ from the Cocos Islands (Whiting et al. 2008). Drifters traveled broadly west and south and did not encounter land until crossing the Indian Ocean and reaching the coasts of Madagascar and East Africa ( $>5000 \mathrm{~km}$ away). Only two drifters passed close to other land masses within a $3000 \mathrm{~km}$ buffer of the natal area (dashed line), drifting near Indonesia and into the Bay of Bengal. (e) Coastal shuttling loggerhead turtles $(n=12)$ from North Carolina (Hawkes et al. 2007). Drifters traveled in the North Atlantic gyre to eastern Atlantic coastal habitats $>5000 \mathrm{~km}$ away. Turtles traveled north or south along the coast to fixed/seasonal coastal habitats rather than migrating away from the mainland. (f) Leatherback $(n=9)$ and loggerhead $(n=3)$ turtles from South Africa (Luschi et al. 2006). The foraging movements of leatherback turtles were in close association with the southward flowing Agulhas Current and areas of high eddy activity. However, three loggerhead turtles migrated north along the coast. Drifters entered both the Indian and South Atlantic Oceans, transporting cheloniid hatchlings too far away from their natal area for turtles to return as adults. Symbols follow those detailed in Fig. 3, however black circles (f) correspond to high-use areas (occupied by $\geq 1$ leatherback turtles). 
time migrants is essentially to follow a certain compass bearing, and the efficiency of this system may be updated in subsequent trips through learned behaviors (e.g., Perdeck 1958, Berthold and Helbig 1992, Pettit et al. 2013). This innate behavior in birds is likely operating successfully in a fairly simple broad-scale landscape of suitable foraging environments, so a straightforward rule for first-time migrants (e.g., "head west-southwest," as in the case of starlings in Europe; Perdeck 1958) may suffice. It may be that such a simple system in sea turtles, i.e., for adults to simply follow an innate compass heading on their first post-nesting migration, is less reliable than returning to suitable foraging grounds they have previously encountered.

While it is widely accepted that ocean currents drive the general dispersion of hatchlings from their natal beaches, and as suggested here, the ontogeny of their subsequent breeding migrations, there is growing evidence that small amounts of active directional swimming based on perception of the local geomagnetic field at favorable range limits (Lohmann et al. 2001) can help reduce the probability of advection to unfavorable areas (e.g., Scott et al. 2012b). Since hatchlings have not been observed to show any geomagnetic directional swimming responses within favorable range limits (Lohmann et al. 2001), there is no evidence for any innate behavior that may alter the general dispersal pathways of turtles drifting along safe trajectories. Essentially, directional swimming may reduce the proportion of drift scenarios that are unsuccessful, in that they lead to hatchling death (e.g., through cold stunning at high latitude waters) or drift to very distant mainland sites that adults do not subsequently return to. However, even if hatchlings embark on periods of directional swimming, predominant drift patterns will be dominated by the ambient current flows (Putman et al. 2012, Scott et al. 2012a, b). Consequently, any assumptions of directional swimming by hatchlings will not undermine our central conclusions that adult foraging sites reflect hatchling drift experiences. Furthermore, we looked at the first year of drift only, because as turtles develop, their dispersal becomes less passive with increasing size and swimming strength. While assumptions of current-induced hatchling drift are reasonable, extreme weather events like large storms can displace hatchling sea turtles thousands of kilometers along aberrant dispersal routes not well sampled by surface drifter buoy data or fully represented in model simulations (Monzón-Argüello et al. 2012). With increased storm activity predicted under future climate change scenarios (Webster et al. 2005), if hatchling displacements are favorable for survival, storms may play an increasing role in shaping the ontogeny of sea turtle migrations.

By analyzing current flows across years, our analysis will have captured aspects of both intra- and interannual variability in prevailing ocean circulation patterns; the primary determinant of hatchling dispersal. Reassuring- ly, modeled Lagrangian trajectories and in-situ Lagrangian buoy trajectories revealed the same large-scale ocean circulation patterns that were consistent with the circulation patterns generated by other site-specific studies where higher resolution regional models and/or more detailed analysis into intra/interannual variation in ocean currents have been carried out (e.g., Hays et al. 2010). While data from surface drifter buoy data sets are limited in spatial and temporal coverage, the increasing resolution and accuracy of ocean models that can be used to generate millions of Lagrangian drift trajectories (Baltazar-Soares et al. 2014) has great utility for assessing spatially and temporally relevant dispersal patterns of drifting organisms. Lagrangian analyses of ocean currents thus provides the potential to aid the understanding of the movements and migrations of other marine species with passive dispersal life stages such as juvenile fish and plankton (Chapman et al. 2011, Baltazar-Soares et al. 2014) and, hence, will allow the applicability of our conclusions that early-life drift patterns shape adult migration routes to be tested across other taxa. There may be several reasons why foraging site selection based on previous drift has adaptive benefit to sea turtles. Not only may this be an effective way to help ensure that adults find suitable foraging sites, but additionally it may allow new foraging sites to emerge as conditions change. Furthermore, where hatchlings disperse widely to suitable foraging sites, this mechanism may allow many different foraging sites to emerge, helping to reduce the impacts of density-dependent reduced foraging habitat quality and also helping ensure population survival if some foraging sites are quickly degraded. In addition, our evidence suggests that new foraging sites for sea turtles will emerge as a consequence of any changes in ocean circulation impacting hatchling drift scenarios. In short, our results highlight the intimate link between the dispersion patterns for hatchling turtles and the movement of adults, and we suggest that assessing this link between juvenile and adult stages of other marine species may be a fruitful and timely area of research given the wide availability of ocean current modeling techniques and animal movement data sets.

\section{ACKNOWLEDGMENTS}

R. Scott was funded by a Natural Environment Research Council (NERC) PhD studentship supervised by G. C. Hays and R. Marsh, and is currently funded by The Future Ocean. We thank the huge number of people who have been involved in sea turtle tracking studies that have made this review possible. We are also grateful to Jeff Blundell for assistance in the local implementation of the ARIANE trajectory software, and to Andrew Coward and Beverly de Cuevas (National Oceanography Centre; NOC) for making model output from NEMO freely available. We thank Bruno Blanke and Nicolas Grima for freely providing ARIANE to the oceanographic community. NEMO is a state-of-the-art, portable modeling framework developed by a consortium of European institutions, namely the National Centre for Scientific Research (CNRS), Paris, the UK Met Office (UKMO), Mercator-Ocean, and the UK National Environment Research Council (NERC). 
The latter development was funded under the NERC "Oceans 2025 " program. Andrew Yool (NOC) assisted in the animation of particle trajectories shown in the supplementary video.

\section{Literature Cited}

Alerstam, T., A. Hedenstrom, and S. Akesson. 2003. Long distance migration: evolution and determinants. Oikos 103: 247-260.

Alexander, R. M. 1998. When is migration worthwhile for animals that walk, swim or fly? Journal of Avian Biology 29: 387-394.

Baltazar-Soares, M., et al. 2014. Recruitment collapse and population structure of the European eel shaped by local ocean current dynamics. Current Biology 24:104-108.

Baracho-Neto, C. G., E. S. Neto, M. R. Rossi-Santos, L. L. Wedekin, M. C. Neves, F. Lima, and D. Faria. 2012. Site fidelity and residence time of humpback whales (Megaptera novaeangliae) on the Brazilian coast. Journal of the Marine Biological Association of the United Kingdom 92:1783-1791.

Benson, S. R., et al. 2011. Large-scale movements and high-use areas of western Pacific leatherback turtles, Dermochelys coriacea. Ecosphere 2:art84.

Berthold, P., and A. Helbig. 1992. The genetics of bird migration: stimulus, timing, and direction. Ibis 134:35-40.

Block, B. A., et al. 2011. Tracking apex marine predator movements in a dynamic ocean. Nature 475:86-90.

Bowen, B. W., and S. A. Karl. 2007. Population genetics and phylogeography of sea turtles. Molecular Ecology 16:48864907.

Broderick, A. C., M. S. Coyne, W. J. Fuller, F. Glen, and B. J. Godley. 2007. Fidelity and over-wintering of sea turtles. Proceedings of the Royal Society B 274:1533-1538.

Chan, S. K. F., J. K. Chan, L. T. Lo, and G. H. Balazs. 2003. Satellite tracking of the post-nesting migration of a green turtle (Chelonia mydas) from Hong Kong. Marine Turtle Newsletter 102:2-4.

Chapman, J. W., et al. 2011. Animal orientation strategies for movement in flows. Current Biology 21:R861-R870.

Chapman, J. W., J. R. Bell, L. E. Burgin, D. R. Reynolds, L. B. Pettersson, J. K. Hill, M. B. Obsall, and J. A. Thomas. 2012. Seasonal migration to high latitudes results in major reproductive benefits in an insect. Proceedings of the National Academy of Sciences USA 109:14924-14929.

Chapman, J. W., R. L. Nesbit, L. E. Burgin, D. R. Reynolds, A. D. Smith, D. R. Middleton, and J. K. Hill. 2010. Flight orientation behaviors promote optimal migration trajectories in high-flying insects. Science 327:682-685.

Cheng, I. J. 2000. Post-nesting migrations of green turtles (Chelonia mydas) at Wan-An Island, Penghu Archipelago, Taiwan. Marine Biology 137:747-754.

Eckert, S. A., J. E. Moore, D. C. Dunn, S. V. B. Ricardo, K. L. Eckert, and P. N. Halpin. 2008. Modeling loggerhead turtle movement in the Mediterranean: importance of body size and oceanography. Ecological Applications 18:290-308.

Egevang, C., I. J. Stenhouse, R. A. Phillips, A. Petersen, J. W. Fox, and J. R. D. Silk. 2010. Tracking of Arctic terns, Sterna paradisaea, reveals longest animal migration. Proceedings of the National Academy of Sciences USA 107:2078-2081.

Godley, B. J., J. M. Blumenthal, A. C. Broderick, M. S. Coyne, M. H. Godfrey, L. A. Hawkes, and M. J. Witt. 2008. Satellite tracking of sea turtles: where have we been and where do we go next? Endangered Species Research 3:3-22.

Hawkes, L. A., A. C. Broderick, M. S. Coyne, M. H. Godfrey, and B. J. Godley. 2007. Only some like it hot-quantifying the environmental niche of the loggerhead sea turtle. Diversity and Distributions 13:447-457.

Hawkes, L. A., A. C. Broderick, M. S. Coyne, M. H. Godfrey, L. F. Lopez-Jurado, P. Lopez-Suarez, S. E. Merino, N. VaroCrus, and B. J. Godley. 2006. Phenotypically linked dichotomy in sea turtle foraging requires multiple conservation approaches. Current Biology 16:990-995.
Hays, G. C., A. C. Broderick, B. J. Godley, P. Lovell, C. Martin, B. J. McConnell, and S. Richardson. 2002. Biphasal long-distance migration in green turtles. Animal Behavior 64: 895-898.

Hays, G. C., S. Fossette, K. A. Katselidis, P. Mariani, and G. Schofield. 2010. Ontogenetic development of migration: Lagrangian drift trajectories suggest a new paradigm for sea turtles. Journal of the Royal Society Interface 7:13191327.

Hays, G. C., and R. Scott. 2013. Global patterns for upper ceilings on migration distance in sea turtles and comparisons with fish, birds and mammals. Functional Ecology 27:748 756.

Hein, A. M., C. Hou, and J. F. Gillooly. 2012. Energetic and biomechanical constraints on animal migration distance. Ecology Letters 15:104-110.

Hughes, G. R. 1974. The sea turtles of south-east Africa II. The biology of the Tongaland loggerhead turtles Caretta caretta $L$. with comments on the leatherback turtle Dermochelys coriacea $L$. and the green turtle Chelonia mydas $L$. in the study region. Oceanographic Research Institute Investigational Report 36. Durban, South Africa.

Lambardi, P., J. R. E. Lutjeharms, R. Mencacci, G. C. Hays, and P. Luschi. 2008. Influence of ocean currents on longdistance movement of leatherback sea turtles in the southwest Indian Ocean. Marine Ecology Progress Series 353:289301.

Liedvogel, M., S. Akesson, and B. Staffan. 2011. The genetics of migration on the move. Trends in Ecology and Evolution 26:561-569.

Lohmann, K., S. Cain, S. Dodge, and C. M. F. Lohmann. 2001. Regional magnetic fields as navigational markers for sea turtles. Science 294:364-366.

Lohmann, K. J., N. F. Putman, and C. M. F. Lohmann. 2008. Geomagnetic imprinting: a unifying hypothesis of long distance natal homing in salmon and sea turtles. Proceedings of the National Academy of Sciences USA 105:19096-19101.

Luschi, P., J. R. E. Lutjeharms, P. Lambardia, R. Mencaccia, G. R. Hughes, and G. C. Hays. 2006. A review of migratory behavior of sea turtles off southeastern Africa. South African Journal of Science 102:51-58.

Madec, G. 2008. "NEMO ocean engine". Note du Pole de modélisation, Institut Pierre-Simon Laplace (IPSL), France 27:1288-1619.

Monzón-Argüello, C., F. Dell'Amico, P. Morinière, A. Marco, L. F. López-Jurado, G. C. Hays, R. Scott, R. Marsh, and P. L. M. Lee. 2012. Lost at sea: genetic, oceanographic and meteorological evidence for storm-forced dispersal. Journal of the Royal Society Interface 9:1725-1732.

Mouritsen, H., R. Derbyshire, J. Staleicken, O. Mouritsen, B. J. Frost, and D. R. Norris. 2013. An experimental displacement and over 50 years of tag-recoveries show that monarch butterflies are not true navigators. Proceedings of the National Academy of Sciences USA 110:7348-7353.

Mueller, T., R. B. O'Hara, S. J. Converse, R. P. Urbanek, and W. F. Fagan. 2013. Social learning of migratory performance. Science 341:999-1002.

Müller, M., and R. Wehner. 2010. Path integration provides a scaffold for landmark learning. Current Biology 20:13681371

Nichols, W. J., A. Resendiz, J. A. Seminoff, and B. Resendiz. 2000. Transpacific migration of a loggerhead turtle monitored by satellite telemetry. Bulletin of Marine Science 67: 937-947.

Papi, F., P. Luschi, S. Akesson, S. Capogrossi, and G. C. Hays. 2000. Open-sea migration of magnetically disturbed sea turtles. Journal of Experimental Biology 203:3435-3443.

Peckham, S. H., D. Maldonado-Diaz, Y. Tremblay, R. Ochoa, J. Polovina, G. Balazs, P. H. Dutton, and W. J. Nichols. 2011. Demographic implications of alternative foraging strategies in juvenile loggerhead turtles Caretta caretta of 
the North Pacific Ocean. Marine Ecology Progress Series 425:269-280.

Perdeck, A. C. 1958. Two types of orientation in migrating Sturnus vulgaris and Fringilla coelebs as revealed by displacement experiments. Ardea 46:1-37.

Pettit, B., A. Flack, R. Freeman, T. Guilford, and D. Biro. 2013. Not just passengers: pigeons, Columba livia, can learn homing routes while flying with a more experienced conspecific. Proceedings of the Royal Society B 280: 20122160.

Putman, N. F., K. J. Lohmann, E. M. Putman, T. P. Quinn, A. P. Klimley, and D. L. G. Noakes. 2013. Evidence for geomagnetic imprinting as a homing mechanism in Pacific salmon. Current Biology 23:312-316.

Putman, N. F., R. Scott, P. Verley, R. Marsh, and G. C. Hays. 2012. Natal site and offshore swimming influence fitness and long-distance ocean transport in young sea turtles. Marine Biology 159:2117-2126.

Schatz, B., S. Chameron, G. Beugnon, and T. S. Collett. 1999. The use of path integration to guide route learning in ants. Nature 399:769-772.

Scott, R., R. Marsh, and G. C. Hays. 2012a. Life in the really slow lane: loggerhead sea turtles mature late relative to other reptiles. Functional Ecology 26:227-235.

Scott, R., R. Marsh, and G. C. Hays. 2012b. A little movement oriented to the geomagnetic field makes a big difference in strong flows. Marine Biology 159:481-488.

Shaffer, S. A., et al. 2006. Migratory shearwaters integrate oceanic resources across the Pacific Ocean in an endless summer. Proceedings of the National Academy of Sciences USA 103:12799-12802.
Song, X., H. Wang, W. Wang, H. Gu, S. Chan, and H. Jiang. 2002. Satellite tracking of post-nesting movements of green turtles Chelonia mydas from the Gangkou Sea Turtle National Nature Reserve, China, 2001. Marine Turtle Newsletter 97:8-9.

Troëng, S., P. H. Dutton, and D. Evans. 2005b. Migration of hawksbill turtles Eretmochelys imbricata from Tortuguero, Costa Rica. Ecography 28:394-402.

Troëng, S., D. R. Evans, E. Harrison, and C. Lagueux. $2005 a$. Migration of green turtles Chelonia mydas from Tortuguero, Costa Rica. Marine Biology 148:435-447.

Van Dam, R. P., C. E. Diez, G. H. Balazs. L. A. Colón, W. O. McMillan, and B. Schroeder. 2008. Sex-specific migration patterns of hawksbill turtles breeding at Mona Island, Puerto Rico. Endangered Species Research 4:85-94.

Webster, P. J., G. J. Holland, J. A. Curry, and H. R. Chang. 2005. Changes in tropical cyclone number, duration, and intensity in a warming environment. Science 309:1844-1846.

Weinrich, M. 2008. Early experience in habitat choice by humpback whales (Megaptera novaeangliae). Journal of Mammalogy 79:163-170.

Whiting, S., J. Long, and M. S. Coyne. 2007. Migration routes and foraging behavior of olive ridley turtles Lepidochelys olivacea in northern Australia. Endangered Species Research $3: 1-9$.

Whiting, S. D., W. Murray, I. Macraw, R. Thorn, M. Chongkin, and A. U. Koch. 2008. Non-migratory breeding by isolated green sea turtles (Chelonia mydas) in the Indian Ocean: biological and conservation implications. Die Naturwissenschaften 95:355-60.

\section{Supplemental Material}

\section{Appendix A}

Figures showing further hatchling drift scenarios, adult turtle migrations, and associated satellite tracking references (Ecological Archives E095-246-A1).

\section{Appendix B}

A movie showing particle tracking results from 42 turtle nesting sites showing 1-yr-long drift scenarios for hatchlings (Ecological Archives E095-246-A2). 